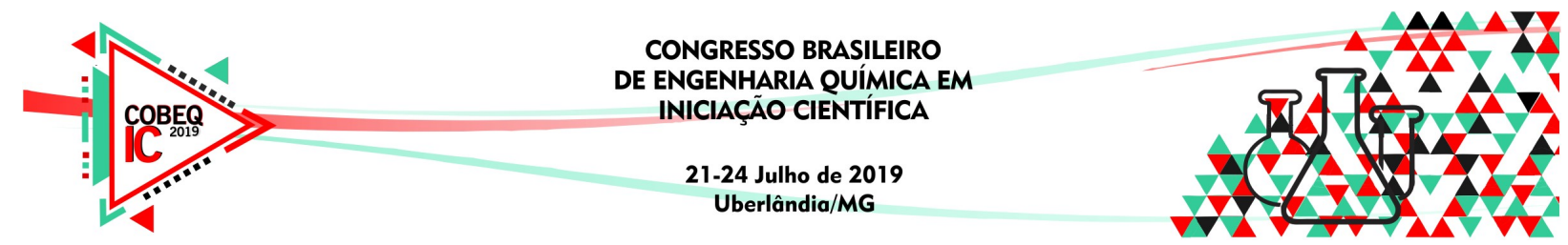

\title{
PRODUÇÃO DE NANOPARTÍCULAS PARA ENCAPSULAÇÃO DE ÓLEO EXTRAÍdO DA SEMENTE DE MARACUJÁ
}

\author{
K. A. RAMOS ${ }^{1}$, L. S. P. OLIVEIRA ${ }^{1}$, R. M. SUZUKI ${ }^{1}$ e C. C. SIPOLI ${ }^{1}$ \\ ${ }^{1}$ Universidade Técnológica Federal do Paraná, Coordenação de Engenharia Química \\ E-mail para contato: kaylana@alunos.utfpr.edu.br
}

\begin{abstract}
RESUMO - Cascas e sementes de frutas são comumente descartadas como resíduos dos processos industriais. O óleo extraído da semente de maracujá apresenta características interessantes para a indústria cosmética e farmacêutica. Como o óleo tem baixa solubilidade em água e apresenta sensibilidade quando exposto às condições ambientes, com o intuito de aumentar o tempo de vida útil, a microencapsulção é uma alternativa. A microencapsulação é o processo de incorporação de compostos em sistemas extremamente pequenos e o conteúdo é liberado de forma controlada. Desta maneira, o objetivo deste trabalho foi a produção de sistemas nanoparticulados denominados lipossomas, para encapsulação do óleo da semente de maracujá. O método utilizado para produção dos lipossomas foi o de injeção de etanol, um método de fácil reprodução e escalonável, tornando-o atrativo para produção industrial. Na primeira fase desse trabalho foram produzidos os lipossomas e na segunda etapa realizou-se a encapsulação do óleo nos lipossomas. Foram testadas diferentes concentrações de lipídios para a produção dos sistemas, adicionando posteriormente diferentes frações de óleo para encapsulação. As amostras foram analisadas em termos de tamanho e polidispersidade.
\end{abstract}

\section{INTRODUÇÃO}

As cascas e sementes das frutas são comumente descartadas dos processos industriais como resíduos, sendo que podem apresentar maior teor de nutrientes quando comparados à polpa (Santos et al., 2011). As sementes de maracujá, resíduos industriais provenientes do processo de esmagamento da fruta para a obtenção do suco, atualmente são descartadas e o valor que pode ser agregado a estes subprodutos é de interesse econômico, científico e tecnológico (Ferrari et al., 2004). De acordo com Ferrari et al. (2004), as sementes de maracujá possuem em torno de $25,7 \%$ de óleo e teor proteico de $15,62 \%$, sendo também ricas em fibras. Sendo assim, a extração do óleo da semente de maracujá (OM), gera uma contribuição social, ambiental e econômica.

Expostos, esses compostos têm seu tempo de vida útil reduzido, já que sofrem com a exposição à luz, calor, umidade e variação de pH (Favaro-Trindade et al., 2008). Por isso, a microencapsulação é eficiente para a sua proteção. A microencapsulação é o processo de empacotamento de materiais particulados em cápsulas extremamente pequenas, as quais podem liberar o conteúdo de forma controlada e condições específicas. As vantagens da 


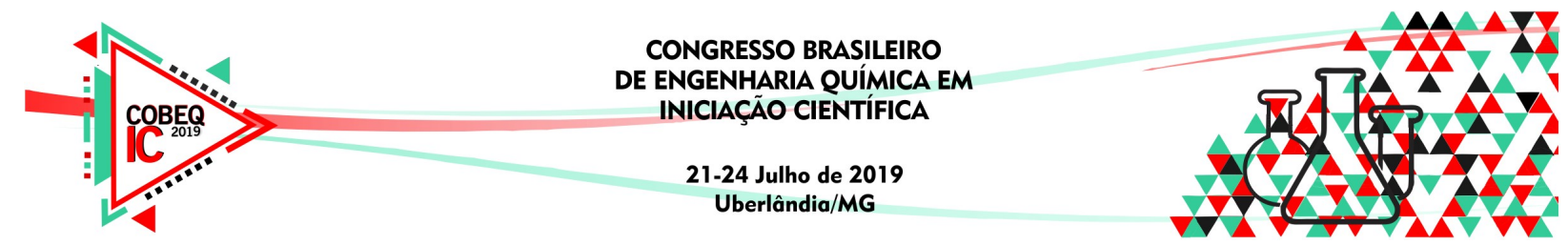

microencapsulação do OM estão no aumento da solubilidade em água, redução dos odores indesejados para aplicação final, diminuição da volatilidade e reatividade e prolongamento da vida útil dos compostos bioativos do óleo (Favaro-Trindade et al., 2008).

Várias técnicas podem ser utilizadas para produção de nanocápsulas, a escolha do método de encapsulação para uma aplicação específica depende de uma série de fatores, como as propriedades físicas e químicas do material encapsulado e das cápsulas, e do tamanho de partículas requerido. Uma boa alternativa para encapsulação do OM são os lipossomas. Os lipossomas são estruturas esféricas, com diâmetros que variam de nanômetros até micrômetros, que em solução aquosa se organizam em uma ou mais bicamadas de fosfolipídios em forma de vesículas (Diniz, 2008). Devido à sua natureza anfifílica, os lipossomas podem incorporar substâncias tanto hidrofílicas quanto hidrofóbicas, sendo que, dependendo da característica do material a ser encapsulado, este pode ficar aprisionado no compartimento aquoso ou inserido entre as bicamadas, respectivamente (Batista et al., 2007). Os lipossomas apresentam-se como sistemas úteis para proteção de produtos biologicamente ativos frente à sua inativação no organismo (Diniz, 2008).

O método escolhido para a produção de lipossomas e encapsulação do óleo é o de injeção de etanol. Essa técnica é muito utilizada devido à facilidade de escalonamento e otimização do processo causado ao longo dos avanços tecnológicos, que fazem da mesma uma técnica consolidada, em que se tem a compreensão dos impactos das variáveis do sistema nas características dos lipossomas e a fenomenologia envolvida (Zômpero, 2013). O método de injeção de etanol também é considerado um método mais econômico, pois não é necessária a utilização de homogeneizadores de alta pressão ou de microfluidizadores (Toniazzo et al., 2015).

\section{MATERIAIS}

\subsection{Substâncias e Reagentes}

- Lecitina de soja com massa molar média de 760 g/mol (Solae CompanyTM, St. Louis,USA);

- Álcool etílico;

- Água destilada;

- Óleo extraído da semente de maracujá (OM).

\section{METODOLOGIA}

\subsection{Extração do Óleo da Semente de Maracujá (OM)}

Com base e na metodologia escrita Bligh e Dyer (1989), os lipídios das sementes de maracujá foram extraídos utilizando diclorometano-etanol-água. Para isso, foi necessário o estudo de solubilidade dos solventes para esta mistura. Os ésteres de ácidos graxos foram separados em um cromatógrafo a gás (Shuimaszu GC-2010 Plus), equipado com coluna RT2560 (100 m de comprimento, 0,2 $\mu \mathrm{m}$ de espessura do filme e 0,25 mm de diâmetro interno), 


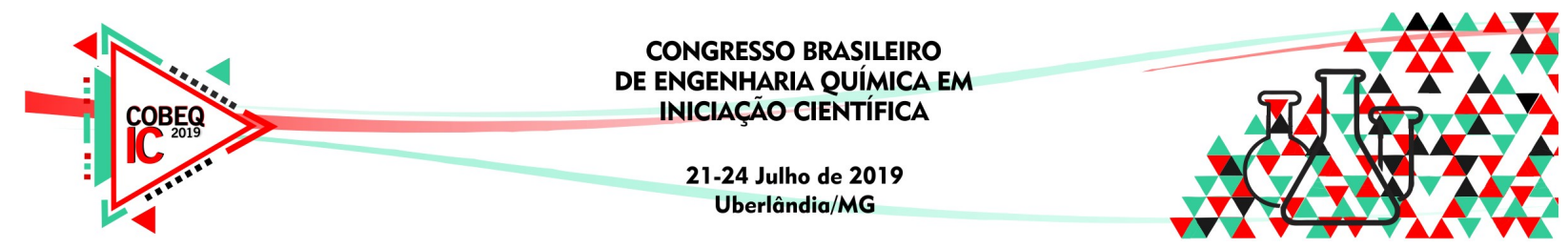

conforme Martin et al. (2008). As injeções foram realizadas em duplicata e volume injetado de $2 \mu \mathrm{L}$ (Martin et al., 2008).

\subsection{Método de Produção de Lipossomas}

Foi empregado o método de injeção de etanol, de acordo com Zômpero (2015). O lipídio é dispersado em etanol em temperatura acima de sua transição de fases em banho ultrassônico, até completa dissolução do mesmo, formando assim a fase orgânica. Foram testadas diferentes concentrações de lipídios: 2,32 mM, 4,64 mM, 6,96 mM e 9,32 mM e, em condições de temperaturas que variaram em uma faixa de $55{ }^{\circ} \mathrm{C}$ até $62{ }^{\circ} \mathrm{C}$. A injeção da fase orgânica em água foi realizada com temperatura controlada considerando uma razão de $10 \%$ v/v de solução orgânica em água, com vazão aproximada de $30 \mathrm{~mL} / \mathrm{min}$ (Zômpero, 2015). Na produção de lipossomas com óleo, o óleo era dissolvido no etanol e variou-se de 1 até $5 \%$ $(\mathrm{m} / \mathrm{m})$ a quantidade de óleo em relação à massa de lipídios.

\subsection{Caracterização das partículas}

As caracterizações das partículas foi realizada considerando o diâmetro hidrodinâmico médio e o índice de polidispersidade das nanopartículas que foram avaliadas por meio da técnica de espalhamento de luz dinâmico (Dynamic Light Scattering - DLS). Após a preparação dos lipossomas contendo o OM, é possível identificar a presença de óleo tanto nos lipossomas (fração encapsulada), como também no meio aquoso (fração não encapsulada). Sendo necessária a separação da forma livre para quantificação do mesmo, e podendo determinar dessa forma a eficiência de encapsulação. Algumas técnicas se destacam para realizar a separação, como a cromatografia de troca iônica e a ultrafiltração (Favaro-Trindade et al., 2008).

\section{RESULTADOS E DISCUSSÕES}

Esse trabalho foi divido em duas partes, com o objetivo de avaliar a formação de lipossomas pelo método de produção adotado (injeção de etanol) e posteriormente, foi-se realizado a encapsulação do óleo de maracujá contendo os compostos bioativos. A caracterização prévia do óleo extraído é apresentada antes dos resultados de produção dos lipossomas.

\subsection{Características Físico-Químicas do Óleo da Semente de Maracujá}

A umidade de um alimento está relacionada à sua estabilidade, qualidade e composição. $\mathrm{O}$ valor de umidade obtido nas sementes de maracujá foi de $4,43 \pm 0,028 \%$, esse valor indica que a semente possui uma baixa umidade. As sementes de maracujá são consideradas boas fontes de ácidos graxos essenciais. O principal ácido graxo encontrado foi o ácido palmítico (16:0), seguido do ácido esteárico (18:0). O ácido oleico (18:1n9), foi o ácido graxo que teve maior destaque entre os ácidos monoinsaturados, estando de acordo com os resultados obtidos por Kobori e Jorge (2005) e Schieber et al. (2001). A ingestão de ácido oleico está relacionada com a redução do nível de baixa densidade lipoproteínas (LDL) e, consequentemente, a prevenção de arteriosclerose (Kobori e Jorge, 2005; Shieber et al., 2001). 


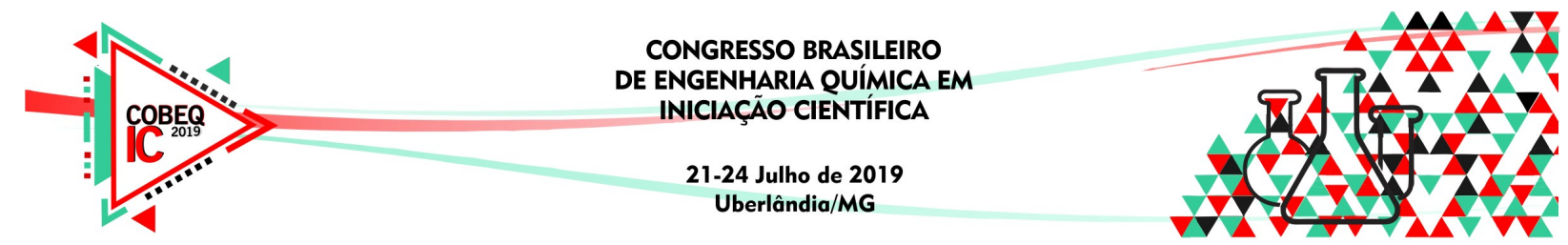

\subsection{Produção de Lipossomas}

A tabela 1 apresenta os dados de produção e da caracterização de lipossomas em 3 concentrações diferentes anteriormente à incorporação do óleo. A variação de temperatura $(\mathrm{T})$ foi mantida entre $50-60^{\circ} \mathrm{C}$ e sob agitação, conforme descrito por Zômpero (2015). Na Tabela 1 são apresentados os dados dos diâmetros médios das amostras em cada concentração (C) e da polidispersidade dos lipossomas com seus respectivos desvios padrão (DP), algo que é ilustrado também na figura 1 .

Tabela 1 - Caracterização físico-química e condições da produção de lipossomas

\begin{tabular}{|c|c|c|c|c|}
\hline $\mathrm{C}(\mathrm{mM})$ & $\mathrm{T}\left({ }^{\circ} \mathrm{C}\right)$ & Rotação $(\mathrm{rpm})$ & Diâmetro \pm DP $(\mathrm{nm})$ & Polidispersidade \pm DP \\
\hline \hline 2,32 & $50-60$ & 1338 & $117,05 \pm 0,45$ & $0,218 \pm 0,018$ \\
\hline 4,64 & $50-60$ & 1338 & $112,70 \pm 0,70$ & $0,275 \pm 0,003$ \\
\hline 6,96 & $50-60$ & 1338 & $117,85 \pm 1,25$ & $0,259 \pm 0,002$ \\
\hline
\end{tabular}

Figura 1 - Gráfico de Diâmetro Médio e Polidispersidade com Desvio Padrão.

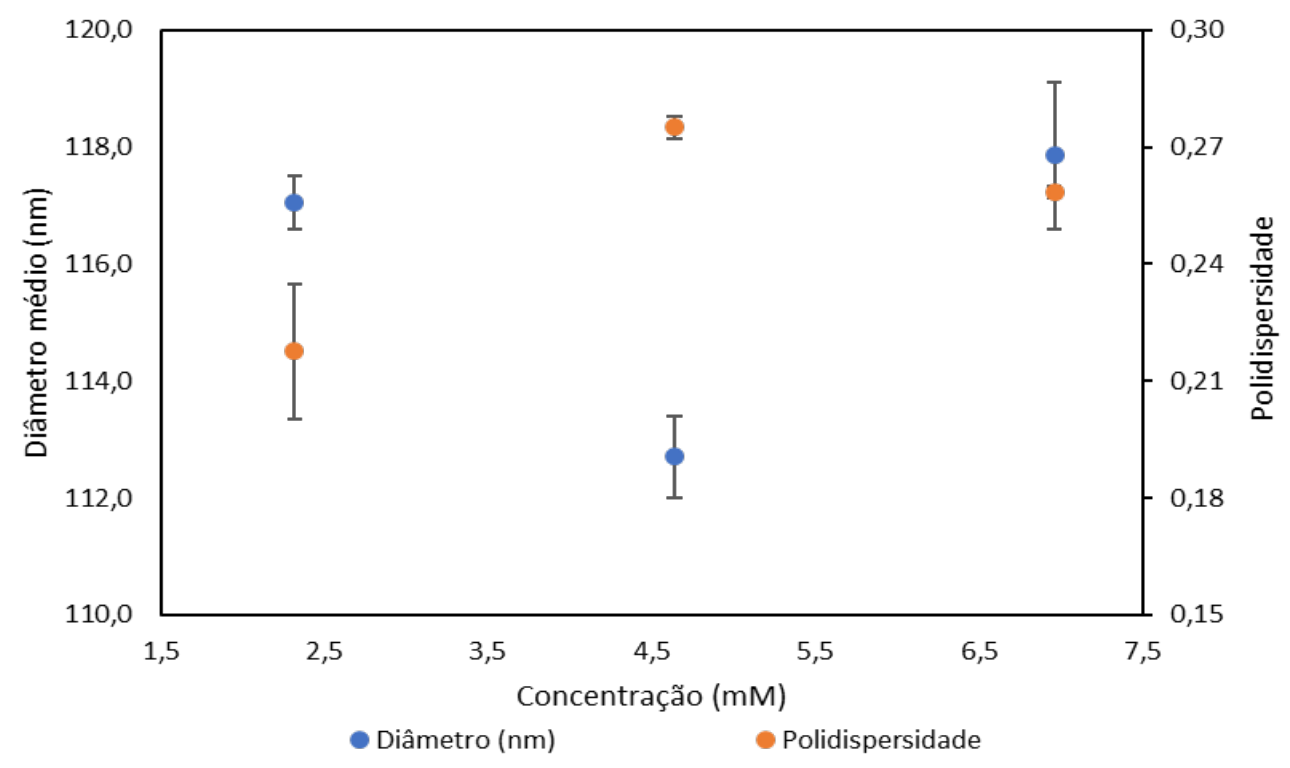

Os dados de polidispersidade apresentaram-se interessantes para futuras aplicações, visto que os valores foram baixos e pouco variavam dentre as concentrações estudadas. Estudos posteriores serão realizados para verificar a variação de PDI em maiores concentrações lipídio.

As análises de tamanho das partículas e polidispersidade nas amostras estudadas foram feitas pela técnica de dispersão dinâmica de luz (do inglês, Dynamic Light Scattering). Essa técnica analisa o movimento browniano determinando o coeficiente de difusão das partículas e o relaciona com o seu tamanho, quanto maior a partícula, mais lento será seu movimento. A fim de determinar quanto de óleo está, efetivamente, sendo encapsulado e a fração de óleo que fica dispersa em solução, será desenvolvida metodologia e os resultados dos testes serão apresentados futuramente.

\subsection{Estudo da incorporação de OM em lipossomas}




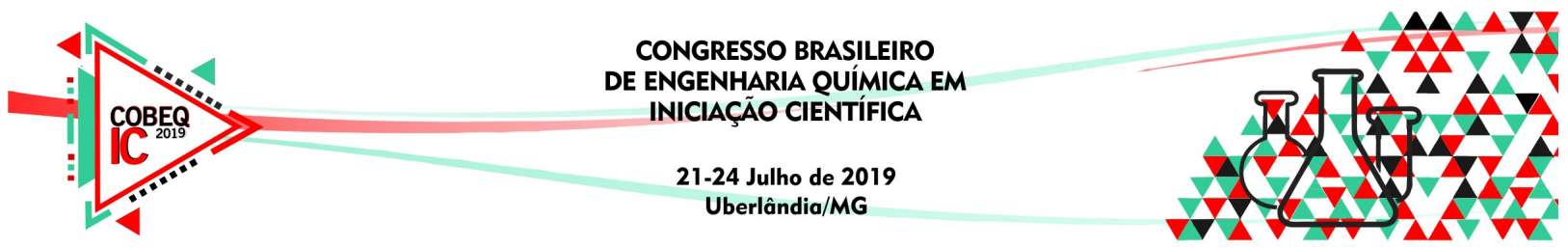

Inicialmente, para os testes de encapsulação do óleo variou-se a concentração dos lipídios entre 2,32 até $6,96 \mathrm{mM}$. Para concentração de óleo a faixa foi de 1,85 até $8,2 \%$ em termos da massa de lipídio presente. As tabelas 2 e 3 apresentam as diferentes condições estudadas. Na tabela 3, devido à limitação de equipamento, utilizou-se um agitador que apresenta a velocidade de agitação em níveis e utilizou-se o nível 1 do mesmo.

Tabela 2 - Caracterização físico-química e condições de encapsulação

\begin{tabular}{|c|c|c|c|c|c|}
\hline $\mathrm{C}(\mathrm{mM})$ & Óleo $(\%)$ & $\mathrm{T}\left({ }^{\circ} \mathrm{C}\right)$ & Rotação $(\mathrm{rpm})$ & Diâmetro $(\mathrm{nm})$ & Polidispersidade \\
\hline \hline 2,32 & 1,85 & 60 & 1988 & 107,3 & 0,273 \\
\hline 2,32 & 2,04 & 58 & 1994 & 105,5 & 0,277 \\
\hline 4,64 & 1,94 & 60 & 1996 & 107,4 & 0,278 \\
\hline 4,64 & 2,03 & 54 & 1997 & 102,9 & 0,248 \\
\hline 6,96 & 1,93 & 54 & 1995 & 111,9 & 0,247 \\
\hline 6,96 & 2,03 & 55 & 1993 & 108,3 & 0,254 \\
\hline
\end{tabular}

Tabela 3 - Caracterização físico-química e condições de encapsulação

\begin{tabular}{|c|c|c|c|c|}
\hline $\mathrm{C}(\mathrm{mM})$ & Óleo $(\%)$ & $\mathrm{T}\left({ }^{\circ} \mathrm{C}\right)$ & Diâmetro $(\mathrm{nm})$ & Polidispersidade \\
\hline \hline 2,32 & 5,13 & 62 & 116,6 & 0,272 \\
\hline 2,2 & 4,90 & 60 & 119,3 & 0,271 \\
\hline 4,64 & 4,93 & 60 & 131,1 & 0,256 \\
\hline 4,64 & 4,94 & 58 & 110,8 & 0,237 \\
\hline
\end{tabular}

De acordo com a análise de tamanho e polidispersidade pode-se observar que em todos os casos tanto na produção de lipossomas como na produção de lipossomas com incorporação de OM temos variações relativamente pequenas. A tendência em termos de diâmetro médio é observar o aumento conforme o aumento de concentração de lipídio e de concentração de óleo (Gómez-Mascaraque et al., 2017).

\section{CONCLUSÕES}

Os dados apresentados revelaram o potencial de estudos do OM e a incorporação em sistemas particulados. Diversos trabalhos na área farmacêutica, cosmética e alimentícia vêm sendo feitos de modo a se garantir a proteção de compostos com características bioativas. $\mathrm{O}$ $\mathrm{OM}$ apresenta características importantes e com isso a sua proteção se faz necessária para diversas aplicações. Além disso, um grande diferencial do trabalho é a utilização de um resíduo para a geração de um produto com valor agregado.

O sistema escolhido para incorporação do OM possui diversas vantagens conforme mostrado anteriormente, e os dados obtidos em termos de tamanho e polidispersidade foram satisfatórios. No entanto, como não se observou uma variação grande de tamanho nas maiores concentrações de lipídio e óleo será importante reavaliar esta condição. Outra análise que poderá ajudar na confirmação do tamanho dos lipossomas é a microscopia eletrônica de transmissão (MET) que em condições específicas apresenta imagem da partícula e com isso é possível avaliar a morfologia e o tamanho e comparar com os resultados de espalhamento de luz dinâmica. 


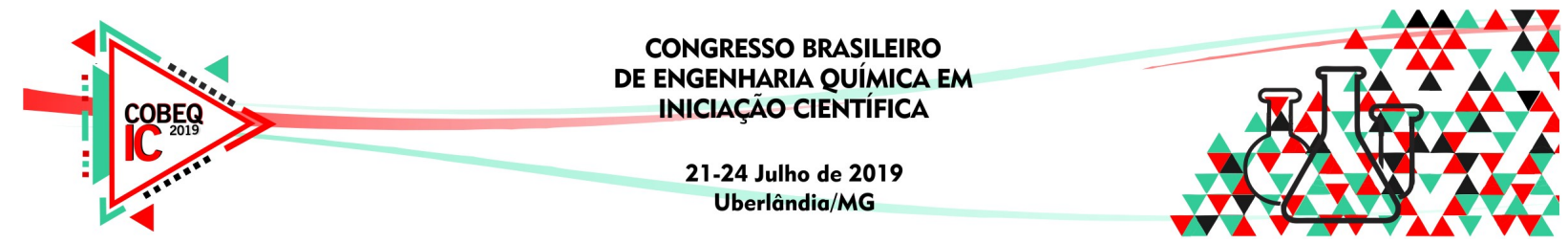

\section{REFERÊNCIAS}

BATISTA, C. M.; CARVAlHO, C. M. B.; MAGALHÃES, N. S. S. Lipossomas e suas aplicações terapêuticas: estado da arte. Revista Brasileira de Ciências Farmacêuticas, v. 43 n. 2, p. 142-151, abr./jun. 2007.

DINIZ, D. G. A. Obtenção, caracterização e avaliação da citotoxicidade sobre células neoplásicas da isotretinoína encapsulada em lipossomas e nanocápsulas poliméricas. 2008. 158 p. Tese (Doutorado em Ciências da Saúde). Universidade de Brasília, Brasília, 2008.

FAVARO-TRINDADE, C. S.; PINHO, S. C.; ROCHA, G. A. Revisão: Microencapsulação de ingredientes alimentícios. Braz. J. Food Technol., São Paulo, v. 11, n. 2, p. 103-112, abr./jun, 2008.

FERRARI, R.A.; COLUSSI, F.; AYUB, R.A; Caracterização de Subprodutos da Industrialização do Maracujá - Aproveitamento de Sementes. Revista Brasileira de Fruticultura, v. 26, pg. 101-102, 2004.

GÓMEZ-MASCARAQUE, L. G.; SIPOLI; C. C., LA TORRE, L. LÓPEZ-RUBIO, G. A. Microencapsulation structures based on protein-coated liposomes obtained through electrospraying for the stabilization and improved bioaccessibility of curcumin. Food chemistry, v. 233, p. 343-350, out. 2017.

KOBORI, C. N.; JORGE, N. Caracterização dos óleos de algumas sementes de frutas como aproveitamento de resíduos industriais. Cien. Agrotec, v. 29, n. 5, p. 1008 - 1014, 2005.

MARTIN, C. A.; OLIVEIRA, C. C.; VISENTAINER, J. V.; MATSUSHITA, M.; DE SOUZA, N. E. Optimization of the Selectivity of a Cyanopropyl Stationary Phase for the Gas Chromatographic Analysis of Trans Fatty Acids. J. Chromatogr. A, v. 1194, ed. 1, p. 111-117, jun. 2008.

SANTOS, L. P. et. al. Phenolic compounds and fatty acids in diferente parts of Vitis labrusca and V. vinífera grapes. Food Research International, v. 44, n. 5, p. 1414-1418, 2011.

SCHIEBER, A.; STINTZING, F. C.; CARLE, R. By-products of plant food processing as a source of functional compounds - recente developments. Trends Food Sci Technol, v. 12, p. 401-413, nov. 2001.

TONIAZZO, T.; GALESKAS, H.; PINHO, S.C. Produção e caracterização de lipossomas liofilizados encapsulando quercetina. In: Congresso Brasileiro de Sistemas Particulados. 37. São Carlos. Anais. UFSCar, São Carlos - SP, 2015.

ZÔMPERO, R. H. F. Desenvolvimento e otimização do método de injeção de etanol para produção de lipossomas contendo $\beta$-caroteno visando sua aplicação na indústria de alimentos. 95 p. Dissertação (Mestrado em Engenharia Química). Universidade Estadual de Campinas, Campinas, 2013. 